\title{
Sistem Pengelolaan Arsip pada Biro Sekretariat Dan Umum Kantor Lembaga Pendidikan Perkebunan Medan
}

\section{Archive Management System at the General Secretariat office Lembaga Pendidikan Perkebunan Medan}

\author{
Ayu Lestari*, Indra Muda \& Rosmala Dewi \\ Program Studi Administrasi Publik, Fakultas Ilmu Sosial dan Ilmu Politik \\ Universitas Medan Area, Indonesia
}

\begin{abstract}
Abstrak
Tujuan kearsipan adalah untuk menemukan arsip dengan mudah dan cepat bila sewaktu-waktu diperlukan kembali. Penelitian ini dilaksanakan di kantor Lembaga Pendidikan Perkebunan Medan. Penelitian ini dilakukan untuk melihat bagaimana sistem pengelolaan arsip, serta faktor hambatan dalam pengelolaan arsip pada Biro Sekretarit dan Umum kantor Lembaga Pendidikan Perkebunan Medan. Penelitian ini merupakan penelitian kualitatif dan Informan diambil dalam penelitian ini adalah pegawai kantor Lembaga Pendidikan Perkebunan Medan. Berdasarkan hasil penelitian, sistem pengelolaan arsip di kantor Lembaga Pendidikan Perkebunan Medan meliputi bagaimana proses pelaksanaannya mulai dari pencatatan, penyimpanan, pemeliharaan, penataan dan pemindahan, hingga pemusnahan arsip. Adapun hambatan-hambatan dalam pengelolaan arsip adalah tidak adanya ruangan khusus untuk menyimpan arsip dan juga tidak adanya pegawai khusus untuk mengelola arsip. Upaya-upaya yang dilakukan dalam pengelolaan arsip yaitu sebaiknya menambahkan sarana dan prasarana arsip agar lebih mudah dan teratur, membuat usulan untuk menyediakan pegawai khusus kearsipan, serta menerapkan sistem otomasi pada pengelolaan arsip yaitu pengolahan secara elektronik dengan pemanfaatan fasilitas komputer dan teknologi informasi lainnya.

Kata Kunci: Sistem, Pengelolaan Arsip
\end{abstract}

\begin{abstract}
The purpose of archiving is to find archives easily and quickly if at any time it is needed again. This research was conducted at the Medan Plantation Education Institute office. The formulation of the problem in this study is how the file management system, and the obstacles in managing the records of the Medan Plantation Education Office. This research uses qualitative research that describes the records management system. Informants in this study were employees of the Medan Plantation Education Office. Based on the results of the study, the archive management system carried out at the Medan Plantation Education Office office covers how the implementation process starts from recording, storing, maintaining, structuring and transferring, to destroying the archive. The obstacles in managing archives are the absence of a special room for storing archives and also the absence of special staff to manage the archives. Efforts made in managing archives are to add facilities and infrastructure of archives to make it easier and orderly, making proposals to provide special staff to handle archives, as well as implementing an automation system in records management, namely electronic processing using computer facilities and other information technology
\end{abstract}

Keywords: System, Archive management

How to Cite: Lestari, A. Muda, I. \& Dewi, R. (2019). Sistem Pengelolaan Arsip Pada Biro Sekretariat Dan Umum Kantor Lembaga Pendidikan Perkebunan Medan. Jurnal Ilmu Pemerintahan, Administrasi Publik, Ilmu Komunikasi (JIPIKOM), 1(1) 2019: 42-47,

*E-mail: ayulestari@gmail.com 


\section{PENDAHULUAN}

Arsip adalah kumpulan dokumen kegiatan atau sumber informasi dengan berbagai macam bentuk yang dibuat oleh organisasi atau instansi maupun perseorangan yang disimpan secara teratur. Pengelolaan arsip pada dasarnya merupakan salah satu kegiatan yang ditujukan untuk mengelola segala dokumen-dokumen yang ada. Pengelolaan arsip di Indonesia diatur dalam Undang - undang Republik Indonesia Nomor 43 Tahun 2009 tentang Kearsipan menerangkan bahwa yang dimaksud dengan kearsipan adalah hal-hal yang berkenaan dengan arsip. Pada kenyataannya masih banyak kantor-kantor yang belum melakukan pengelolaan arsip dengan baik. Kenyataan bahwa bidang kearsipan belum mendapat perhatian khusus dalam jaringan informasi, maka dipandang perlu untuk segera memberikan petunjuk kerja yang praktis tentang bagaimana seharusnya arsip-arsip tersebut diterima, disimpan dan dipergunakan kembali.

Lembaga Pendidikan Perkebunan Medan (LPP) berbentuk Badan Hukum Asosiasi yang beranggotaan seluruh BUMN Perkebunan (BUMN PTPN). Lembaga Pendidikan Perkebunan (LPP) berkantor pusat di Yogyakarta dan cabang berada di Medan. Lembaga Pendidikan Perkebunan merupakan organisasi atau instansi yang memiliki stuktur, tugas dan fungsi serta tanggung jawab, tentu perlu adanya pengelolaan arsip yang efektif. Sistem merupakan sebuah kesatuan dari seluruh bagian yang saling berkaitan di mana keberadannya terdapat disuatu wilayah atau bagian yang mempunyai item-item di dalamnya. Sistem adalah suatu jaringan kerja dari prosedur-prosedur yang saling berhubungan, berkumpul bersama-sama untuk melakukan suatu sasaran yang tertentu. (Jogiyanto, 2005). Pengelolaan adalah proses yang memberikan pengawasan pada semua hal yang terlibat dalam pelaksanaan kebijaksanaan dan pencapaian tujuan tertentu. Pengelolaan sama dengan manajemen yaitu penggerakan, pengorganisasian dan pengarahan usaha manusia untuk memanfaatkan secara efektif material dan fasilitas untuk mencapai tujuan organisasi.

Pengelolaan adalah seni dan ilmu perencanaan, pengorganisasian, penyusunan, pengarahan, dan pengawasan sumber daya untuk mencapai tujuan yang sudah ditetapkan (Manullang, 2012). Tujuan pengelolaan adalah agar segenap sumber daya yang ada seperti, sumber daya manusia, peralatan atau sarana yang ada dalam suatu organisasi dapat digerakkan sedemikian rupa, sehingga dapat menghindarkan dari segenap pemborosan waktu, tenaga dan materi guna mencapai tujuan yang diinginkan. (Zulhairi, Batubara \& Hasibuan, 2013; Manurung, Warjio \&, Kariono, 2016). Pengelolaan dibutuhkan dalam semua organisasi, karena tanpa adanya pengelolaan atau manajemen semua usaha akan sia-sia dan pencapaian tujuan akan lebih sulit (Lisnawati \& Kadir, 2014; Lindawati \& Lubis, 2016).

Arsip meliputi tiga pengertian (Sedarmayanti, 2003), yaitu: Kumpulan naskah atau dokumen yang disimpan, Gedung (ruang) penyimpanan kumpulan naskah atau dokumen, Organisasi atau lembaga yang mengelola dan menyimpan kumpulan naskah atau dokumen. Menurut Undang-undang No 43 Tahun 2009 tentang kearsipan, arsip adalah rekaman kegiatan atau peristiwa dalam berbagai bentuk dan media sesuai dengan perkembangan teknologi informasi dan komunikasi yang dibuat dan diterima 
oleh lembaga Negara, pemerintahan daerah, lembaga pendidikan, perusahaan, organisasi politik, organisasi kemasyarakatan, dan perseorangan dalam pelaksanaan kehidupan bermsyarakat, berbangsa dan bernegara (Musliichhah, 2016). Terdapat beberapa jenis arsip yang dijelaskan dalam buku Mengelola dan Menjaga Sistem Kearsipan (Endang, 2009:9) diantaranya: Berdasarkan bentuk fisiknya terbagi dua, yaitu: Arsip yang berbentuk lembaran dan Arsip yang tidak berbentuk lembaran. Berdasarkan sifatnya terbagi atas lima, yaitu: Arsip tidak penting, Arsip biasa, Arsip Penting, Arsip sangat penting, dan Arsip rahasia. Berdasarkan fungsinya terbagi atas tiga jenis, yaitu: Arsip dinamis, dan Arsip Statis. Berdasarkan nilai guna antara lain: Nilai penerangan, Nilai yuridis, Nilai historis, Nilai Ilmiah, Nilai guna fiscal

Peran utama arsip adalah sebagai alat ingat atau memori suatu perusahaan atau organisasi. Mengingat pentingnya memori dalam kehidupan manusia, dalam organisasi pun memori sangatlah penting, sehingga memori tersebut jangan sampai hilang atau rusak dan harus dijaga dengan sungguh-sungguh. Selain sebagai memori perusahaan, arsip juga mempunyai peran sebagai pengambil keputusan, sebagai bahan bukti, dan sebagai akuntabilitas. Yang dimaksud dengan sebagai pengambil keputusan adalah menentukan berhasil atau tidaknya suatu organisasi atau instansidalam mencapai tujuannya. Fungsi arsip menurut Sugiarto (Sugiarto \& T, 2005:9) yaitu: Arsip sebagai sumber ingatan atau memori; Arsip sebagai bahan pengambilan keputusan; Arsip sebagai bukti atau legalitas; Arsip sebagai rujukan historis

Tujuan Arsip menurut (Barhtos, 2007) adalah untuk menjamin keselamatan bahan pertanggungjawaban nasional tentang perencanaan, pelaksanaan, penyelenggaraan kehidupan bangsa serta untuk menyediakan bahan pertanggungjawaban, tersebut bagi kegiatan pemerintah. Menurut Badri Munir Sukoco (2007) pengelolaan arsip adalah proses penataan, penyimpanan, peminjaman, penemuan kembali, pemeliharaan, pengamanan dan penyusutan dokumen baik dokumen fisik/manual maupun dokumen elektronik dan sebagai proses yang menitikberatkan pada efisiensi administrasi. Terdapat azas-azas dalam pengelolaan arsip yaitu: Sentralisasi (Pemusatan), Azas sentralisasi dalam pengelolaan arsip adalah penyelenggaraan kearsipan dipusatkan pada satu unit tertentu; Desentralisasi (Penyebaran), Azas desentralisasi dalam pengelolaan arsip adalah penyelengaraan arsip dilakukan oleh masing-masing unit. Dalam hal ini semua unit kerja dapat menggunakan sistem penyimpanan yang sesuai dengan ketentuan unit yang bersangkutan.

Gabungan (kombinasi sentralisasi an desntralisasi), Azas gabungan adalah pelaksanaan pengelolaan arsip dengan cara menggabungkan antara azas sentralisasi dengan desentralisasi. Azas ini digunakan untuk mengurangi dampak kerugian yang terdapat pada azas sentralisasi dan desentralisasi. Dalam penanganan arsip secara kombinasi, arsip yang masih aktif digunakan atau disebut arsip aktif dikelola di unit kerja masing-masing bagian, dan arsip yang sudah kurang dipergunakan atau disebut dengan arsip inaktif dikelola di sentral arsip.

Tata cara penyimpanan arsip menurut (Barhtos, 2007) atau disebut dengan istilah filling adalah proses peraturan dan penyimpanan bahan-bahan secara sistematis, sehingga bahan-bahan tersebut dengan mudah dan cepat ditemukan kembali setiap kali 
diperlukan. Sistem penyimpanan arsip meliputi: Sistem abjad, Sistem suhyek, Sistem Geografis, Sistem nomor, sistem kronologis (penyimpanan menurut tanggal). Pengelolaan arsip menggunakan system otomasi merupakan sistem kearsipan yang menngunakan sarana pengolahan data secara elektronik dengan memanfaatkan fasilitas komputer dan teknologi informasi lainnya. Penggunaan media otomasi arsip bukan saja menjamin efisiensi, tetapi juga mampu mengurangi atau mengembangkan kebutuhan duplikasi apabila hal itu diperlukan. Pengiriman, pemrosesan, penyimpanan dan penemuannya kembali informasi dapat dilakukan melalui sistem yang bekerja secara cepat.

\section{METODE PENELITIAN}

Terkait dengan judul yang diajukan oleh penulis yaitu Sistem Pengelolaan Arsip pada Bagian Sekretariat dan Umum Kantor Lembaga Pendidikan Perkebunan Medan, maka jenis penelitian yang digunakan adalah penelitian kualitatif. Penelitian ini adalah penelitian yang diarahkan untuk memberikan fakta- fakta atau kejadian-kejadian secara sistematis dan akurat mengenai sifat-sifat populasi serta menganalisa kebenarannya berdasarkan data yang diperoleh. Lokasi penelitian dilakukan di Kantor Lembaga Pendidikan Perkebunan Medan, jalan William Iskandar, id 20222.

Pengumpulan data yang menurut adanya pertemuan lansung atau komunikasi langsung antara peneliti dengan orang yang dianggap tahu tentang situasi sosial dan informan. Yang dimaksud dengan informan dalam penelitian ini yaitu orang-orang yang dianggap tahu atau orang-orang yang selalu berurusan dan membutuhkan pelayanan dari organisasi atau instansi. Informan Kunci (Kepala Bagian Sekretariat dan Umum), informan Utama (pegawai Bagian Sekretariat dan Umum), informan tambahan (pegawai kantor Lembaga Pendidikan Perkebunan Medan. Dalam penelitian ini, untuk memperoleh data dan informasi atau keterangan- keterangan yang diperlukan penulis menggunakan metode observasi, waancara, dan dokumentasi. Adapun teknik analisis data yang digunakan meliputi reduksi data, penyajian data, dan verifikasi data atau penarikan kesimpulan

\section{HASIL DAN PEMBAHASAN}

Sistem pengelolaan arsip yang dilakukan kantor Lembaga Pendidikan Perkebunan Medan meliputi bagaimana proses pelaksanaannya mulai dari pencatatan hingga pemusnahan arsip. Pada umumnya biasanya surat menyurat dicatat terlebih dahulu dalam semacam buku yang dinamakan buku agenda. Buku tersebut berfungsi untuk mencatat segala sesuatu yang berkenaan dengan pengiriman surat kepada pihak lain ataupun penerimaan surat-surat masuk. Hal ini diungkapkan oleh Elli Hendarti sebagai Kepala BSU, "'Surat yang masuk dicatat terlebih dahulu, kemudian mereka langsung memberikan kepada bagian biro yang bersangkutan lalu memasukkan surat ke dalam odner (filling kabinet). Begitu juga surat keluar seperti surat jalan (SPJ) yaitu tersedia adanya buku ekspedisi (agenda) di mana proses dokumen harus ada tanggal, nomor surat, perihal, keterangan dan paraf." Berdasarkan wawancara diatas mereka mencatat surat masuk dan surat keluar di buku agenda, seperti surat jalan (SPJ) dan bukti masuk ataupun bukti keluar keuangan di kantor LPP Medan.

Arsip haruslah disimpan dengan baik agar apabila sewaktu-waktu dibutuhkan arsip dapat ditemukan kembali dengan mudah dan cepat. Hal ini diungkapkan oleh Nurkhotimah Sinaga sebagai Kepala BPU," "Sistem penyimpanan arsip di kantor LPP Kampus Medan menggunakan sistem desentralisasi". Dan pendapat ditambahkan oleh 
Suprapto sebagai pegawai BSU," seharusnya ada tempat ruang khusus arsip hanya saja kurang terpenuhi kebutuhan pengarsipan sehingga arsip hanya sebatas di simpan dalam filling kabinet dan lemari saja, itupun di simpan di ruangan masing-masing Biro".

Pemeliharaan arsip dapat dikatakan juga sebagai perawatan arsip. Pemeliharaan merupakan suatu usaha untuk menjaga arsip agar terhindar dari segala sesuatu yang dapat merusak arsip. Hal ini diungkapkan oleh Elli Hendarti sebagai Kepala BSU, "Sebenarnya untuk pemeliharaan arsip di Biro Sekretariat dan Umum cenderung tidak adanya pemeliharaan itu bersifat spontanitas saja". Pernyataan yang serupa diuangkapkan oleh Suprapto sebagai pegawai BSU, "Memang benar tidak adanya pemeliharaan arsip yang khusus hanya saja inisiatif dari Biro masing-masing". Hasil wawancara peneliti di kantor Lembaga Pendidikan Perkebunan Medan menegaskan bahwa tidak memaksimalkan pemeliharaan ataupun perawatan kearsipan dalam pelaksanaan pengelolaan arsip.

Penataan dan pemindahan arsip adalah kegiatan pemindahan arsip-arsip dari arsip aktif hingga arsip tak aktif karena sudah jarang dipergunakan dalam kegiatan seharihari. Hal diungkapkan oleh Elli Hendarti sebagai Kepala BSU, "Penataan arsip di kantor ini masih belum sempurna hanya disimpan di filing kabinet yang sebelumnya saya bilang tadi sesaui nomor surat, subjek hingga tanggal surat". Pernyataan yang sama diungkapkan oleh Nurkhotiamah sebagai kepala BPU, "Pemindahan arsip di kantor ini biasanya diperiksa terlebih dahulu, mana arsip aktif dan tidak aktif. Arsip aktif di letakkan dalam odner sesuai nomor surat maupun subjek surat, sedangkan arsip tidak aktif disusun kedalam box kemudian di letakkan ke gudang kantor". Dari hasil wawancara diatas masih banyak keterbatasan mengenai penataan dan pemindahan arsip, karena tidak adanya ruangan khusus untuk menata arsip.

Tahap akhir dari pengelolaan kearsipan adalah pemusnahan arsip. Pemusnahan arsip adalah kegiatan menghapuskan secara fisik arsip inaktif atau arsip yang telah hilang nilai gunanya, dengan harapan agar arsip yang tersimpan hanya arsip aktif atau arsip yang benar-benar dipergunakan. Hal ini diungkapkan oleh Suprapto sebagai pegawai BSU. "untuk pemusnahan arsip di sini menggunakan alat penghancur kertas dan juga terkadang mereka melakukan dengan cara dibakar". Hal tersebut juga diungkapkan oleh Nurkhotimah sebagai kepala BPU, "biasanya arsip yang sudah tidak dapat digunakan di kumpulkan terlebih dahulu dan diletakkan di bagian gudang". Dari hasil wawancara diketahui, hal yang paling utama untuk pemusnahan arsip yaitu dilakukan dengan memilah-milah arsip aktif dan tak aktif, kemudian mereka melalukan pemusnahan arsip dengan cara menghancurkan arsip menggunakan mesin penghancur kertas hingga pembakaran arsip.

Suatu kegiatan dalam melakukan tugasnya tidak selalu berjalan dengan lancar, tentu saja mempunyai hambatan atau kendala. Beberapa hambatan dalam kegiatan kearsipan. Berdasarkan wawancara yang dilakukan kepada informan di kantor Lembaga Pendidikan Perkebunan Medan masih terdapat hambatan atau kendala dalam melakukan pengelolaan kearsipan yaitu belum adanya pegawai khusus kearsipan, tidak adanya ruangan khusus untuk penyimpanan arsip, dan juga masih kurangnya sarana dan prasarana yang tidak cukup memadai hal ini dapat mengakibatkan terjadinya penumpukan arsip.

\section{SIMPULAN}

Pencatatan surat, mereka mencatat surat masuk dan surat keluar di buku agenda, seperti surat jalan dinas (SPD) dan bukti masuk ataupun bukti keluar keuangan di kantor LPP Medan. Sistem penyimpanan arsip di BSU sesuai subjek, tanggal ataupun 
tahun tergantung pada jenis dokumennya kemudian diletakkan dalam odner. Masih terdapat kurangnya pemeliharaan ataupun perawatan arsip di kantor Lembaga Pendidikan Perkebunan Medan. Penyusutan arsip yang dimulai dari memeriksa arsip aktif dan arsip tidak aktif kemudian di letakkan bagian gudang kantor. Pemusnahan arsip dilakukan dengan dua cara yaitu di hancurkan dengan menggunakan penghancur kertas dan dibakar.

\section{DAFTAR PUSTAKA}

Barhtos, B. (2007). Manajemen Kearsipan. Jakarta: Bumi Aksara.

Endang, S. (2009). Mengelola dan Menjaga Sistem Kearsipan. Jakarta: Erlangga.

Jogiyanto. (2005). Analisis dan Sistem Informasi. Yogyakarta : Andi.

Lindawati dan Lubis, A., (2016). Peranan Kantor Perpustakaan, Arsip dan Dokumentasi dalam Peningkatan Pelayanan bagi Masyarakat, JPPUMA: Jurnal Ilmu Pemerintahan dan Sosial Politik UMA (Journal of Governance and Political UMA), 4 (1): 43-58.

Lisnawati dan Kadir, A. (2014). Proses Penanganan Tata Kearsipan Daerah pada Kantor Perpustakaan Arsip dan Dokumentasi Kabupaten Deli Serdang, JPPUMA: Jurnal Ilmu Pemerintahan dan Sosial Politik UMA (Journal of Governance and Political UMA), 2 (1): 31-44.

Manullang, M. (2012). Dasar-Dasar Manajemen. Yogyakarta: Gadjah Mada University Press.

Manullang, M. (2012). Manajemen Strategi. Bandung: Citapustaka Media Perintis.

Manurung, A.G., Warjio, Kariono, (2016), Penerapan Sistem Informasi Kearsipan Dalam Pelayanan Ketatausahaan Pada Biro Umum Sekretariat Daerah Provinsi Sumatera Utara Jurnal Administrasi Publik (Public Administration Journal), 6 (1): 41-55

Musliichhah. (2016). Bunga Rampai Kearsipan. Yogyakarta: Gadjah Mada University .

Sedarmayanti. (2003). Tata Kearsipan dengan Memanfaatkan Teknologi Modern. Bandung: Penerbit Mandar Bandung.

Sugiarto, A., \& T, W. (2005). Manajemen Kearsipan Modern. Yogyakarta: Gava Media.

Zulhairi, Batubara, B.M., dan Hasibuan, M.A. (2013), Fungsi Penataan Kearsipan Dalam Meningkatkan Kerja Pada Rumah Sakit Jiwa Daerah Provinsi Sumatera Utara, Jurnal Administrasi Publik Universitas Medan Area, 1 (1): 11-15 